\title{
Vapour pressures of hydroxybenzophenone UV absorbers
}

\author{
Duncan M. Price ${ }^{\mathrm{a}, *}$, Michael Hawkins ${ }^{\mathrm{b}}$ \\ ${ }^{a} I P T M E$, Loughborough University, Loughborough LE11 3TU, UK \\ ${ }^{\mathrm{b}}$ BLC Leather Technology Centre, Leather Trade House, King's Park Road, Moulton Park, Northampton NN3 6JD, UK
}

Received 25 August 1998; received in revised form 12 January 1999; accepted 12 January 1999

\begin{abstract}
A thermogravimetric method was used to measure the vapour pressures of a series of hydroxybenzophenone UV stabilisers. Enthalpies of vaporisation were determined from the slope of a plot of the logarithm of the vapour pressure against reciprocal absolute temperature. Enthalpies of sublimation were measured either directly by the same method or by summing the enthalpy of vaporisation with the enthalpy of fusion determined by differential scanning calorimetry. Values of the vapour pressure at the melting temperature are given along with extrapolated values at $25^{\circ} \mathrm{C}$ and the estimated normal boiling temperature. Decreasing the hydrogen bonding potential within a series of compounds increases the volatility whereas increasing molecular weight has the opposite effect. (C) 1999 Elsevier Science B.V. All rights reserved.
\end{abstract}

Keywords: Vapour pressure; Thermogravimetry; UV absorber

\section{Introduction}

Many polymers are particularly susceptible to ultraviolet radiation in the $290-400 \mathrm{~nm}$ region. The absorbtion of this energy causes the macromolecular chains to break; this in turn causes surface crazing, embrittlement, chalking, discoloration, and loss of physical properties such as impact and tensile strength. In order to slow down this process for use in outdoor applications, these materials must be stabilised with an appropriate UV absorber. When selecting an appropriate stabiliser, it is necessary to evaluate the efficiency of a particular compound in terms of its compatibility (solubility) in the polymer, UV absorbtion and potential for loss from the system through diffusion and evaporation. The latter processes may

\footnotetext{
*Corresponding author. Fax: +44-1509-223332; e-mail: d.m.price@lboro.ac.uk
}

cause rapid diminution of stabiliser from the surface, or (if the rate of evaporation is less than the rate of diffusion) lead to undesirable accumulation on the polymer surface. The rate of evaporation is controlled by the vapour pressure of the compound, therefore it is important to know this parameter, not only at high temperatures where processing is typically carried out, but also at lower temperatures when the final product is used outside or under some other conditions (influence of the sun, washing and drying of fibres, etc.).

Benzophenone compounds were the first effective UV stabilisers to be made commercially available and have maintained their position as technologically important materials for use with polystyrene, poly(vinyl chloride) and polypropylene [1]. Whilst there have been a number of studies of the volatility of these compounds [2,3], such data often covers a narrow temperature range or only a few materials of interest. This work was therefore carried out in order to collect 
parameters as part of comprehensive modelling study on the performance of a set of hydroxybenzophenone UV absorbers.

There are several strategies for the determination of vapour pressure [4] - these range from direct measurement using a manometer [5], monitoring the gas phase concentration of the volatile species (by, for example, spectrometry [6,7]), measurement of sample volatilisation by vacuum-effusion (Knudsen cell $[8,9]$ ) or transpiration techniques $[10,11]$ and boiling point determination under controlled pressure $[12,13]$. Gückel and co-workers [14-17] have measured volatilisation rates of pesticides at ambient pressure by isothermal thermogravimetry. Since sublimation and evaporation are zero-order processes, the rate of mass loss of a sample under isothermal conditions due to vaporisation should be constant providing that the free surface area does not change. These studies correlated the rate of mass loss per unit area with the vapour pressure of standard materials over a range of temperatures to derive an empirical method of determining the vapour pressure of compounds whose vapour pressures were unknown. Elder [18] has used the same technique to measure the vapour pressures of pharmaceutical compounds. Thermogravimetry has also been used to study the vaporisation of perfume components, pharmaceuticals and their interactions [19-22]. We have previously reported a method for accurately determining the enthalpies of vaporisation and sublimation of materials by thermogravimetry [23]. Using pure reference materials, a relationship between volatilisation rate and vapour pressure based on the Langmuir equation for free evaporation [24] can be used to calibrate the apparatus. In favourable cases, the melting temperature and enthalpy of fusion can be obtained directly from thermogravimetry [23].

\section{Experimental}

Materials used in this work were obtained from proprietary sources including several experimental UV absorbers. Chemical structure and purity were determined by ${ }^{1} \mathrm{H}-\mathrm{NMR}$ and HPLC-MS in addition to the measurements described below.

Differential scanning calorimetry was carried out using a Mettler DSC 30. Samples were encapsulated in hermetically sealed aluminium pans and heated at $10^{\circ} \mathrm{C} / \mathrm{min}$ under nitrogen (flow rate: $10 \mathrm{ml} / \mathrm{min}$ ). The instrument was calibrated for temperature and heat-flow according to the melting point and enthalpy of fusion of gallium, indium, tin and bismuth.

Thermogravimetry was performed using a TA Instruments TGA 951. The thermobalance was calibrated for temperature according to the method of Stewart [25] using indium, tin, bismuth and lead. The magnitude and linearity of the balance response were checked with standard milligram masses. Samples were placed in tared aluminium sample cups (internal diameter: $12.5 \mathrm{~mm}$ ) of the type used for DSC measurements ${ }^{1}$. The cup was filled completely with material (ca. $50 \mathrm{mg}$ ), which was then melted so that a known surface area was obtained. The thermocouple was kept as close as possible to the surface of the specimen in order to record accurately its temperature without interfering with the operation of the balance. The furnace was purged with dry, oxygen-free nitrogen (flow rate: $100 \mathrm{ml} / \mathrm{min}$ ). Measurements were carried out from $30^{\circ} \mathrm{C}$ to $300^{\circ} \mathrm{C}$ at a heating rate of $1^{\circ} \mathrm{C} \mathrm{min}^{-1}$.

\section{Results and discussion}

Analysis of the thermogravimetric data is based on the Langmuir equation for evaporation in vacuo [24]:

$$
\frac{\mathrm{d} m}{\mathrm{~d} t}=p \alpha \sqrt{\frac{M}{2 \pi R T}}
$$

where $\mathrm{d} m / \mathrm{d} t$ is the rate of mass loss per unit area, $p$ the vapour pressure, $M$ the molecular weight of the effusing vapour, $R$ the gas constant, $T$ the absolute temperature and $\alpha$ is the vaporisation coefficient (usually assumed to be 1 ).

In the case of a material volatilising into a flowing gas stream at one atmosphere rather than in vacuo, $\alpha$ can no longer be assumed to be unity. Rearranging Eq. (1) gives:

$$
p=k v \text {, }
$$

where $k=\sqrt{2 \pi R} / \alpha$ and $v=\mathrm{d} m / \mathrm{d} t \sqrt{T / M}$

The authors have shown that plots of $p$ vs. $\nu$ are colinear for a series of compounds of known vapour pressure [23]. As in the previous study, benzoic acid,

\footnotetext{
${ }^{1}$ Part number 900786.901 from TA Instruments, New Castle, DE, USA.
} 
acetamide, benzophenone and phenanthrene were employed to calibrate the apparatus. We found that $p=0.1274 \nu$ with an $R^{2}$ of 0.998 where $\nu$ is expressed as the rate of mass loss per unit area $\left(\mathrm{mg} / \mathrm{min} / \mathrm{m}^{2}\right)$ multiplied by the square root of the absolute temperature $(K)$ divided by the square root of the molecular weight $(\mathrm{g} / \mathrm{mol})$.

The temperature dependence of the vapour pressure can be described by the Clausius-Clapeyron equation:

$$
\ln p=B-\frac{\Delta H}{R T},
$$

where $\Delta H$ is the molar enthalpy of sublimation $\left(\Delta H_{\text {sub }}\right)$ in the case of a solid or enthalpy of vaporisation $\left(\Delta H_{\mathrm{vap}}\right)$ in the case of a liquid.

Thus the enthalpies of vaporisation and sublimation can be found from the slope of a plot of the natural logarithm of the vapour pressure vs. reciprocal absolute temperature.

At the melting temperature $T_{\mathrm{m}}$ :

$$
\Delta H_{\text {sub }}\left(T_{\mathrm{m}}\right)=\Delta H_{\text {vap }}\left(T_{\mathrm{m}}\right)+\Delta H_{\text {fus }}\left(T_{\mathrm{m}}\right),
$$

where $\Delta H_{\text {fus }}$ is the enthalpy of fusion.

In cases where $\Delta H_{\text {fus }}$ is known (e.g. by DSC), Eq. (4) can be used to estimate the enthalpy of sublimation in cases where the vapour pressure of the solid cannot be determined by this technique. If data can be obtained through the melting region, $\Delta H_{\text {sub }}$, $\Delta H_{\text {vap }}, \Delta H_{\text {fus }}$ and $T_{\mathrm{m}}$ can be measured directly by thermogravimetry [23].

Table 1 lists the molecular weight and enthalpies of fusion, sublimation and vaporisation of the series of UV absorbers. ( $\Delta H_{\text {sub }}, \Delta H_{\text {vap }}$ and $\Delta H_{\text {fus }}$ of $2,4,4^{\prime}-$ trihydroxybenzophenone were determined from its vapour pressure measured by thermogravimetry whereas for the remainder of the series $\Delta H_{\text {fus }}$ determined by DSC was used with $\Delta H_{\text {sub }}$ being found from Eq. (4). For comparison $\Delta H_{\text {fus }}$ determined by DSC for $2,4,4^{\prime}$-trihydroxybenzophenone was $34.0 \mathrm{~kJ} / \mathrm{mol}$ compared to $31.3 \mathrm{~kJ} / \mathrm{mol}$ by this technique. The standard error in $\Delta H_{\text {vap }}$ (determined from the linear regression coefficient of $\ln p$ vs. 1/T [26]) amounts to less than $1 \%$, and the error in $\Delta H_{\text {sub }}$ (determined from the sum $\left.\Delta H_{\text {fus }}+\Delta H_{\text {vap }}\right)$ is less than of $5 \%$.

The data obtained by this technique was used to extrapolate the vapour pressure at the melting temperature of each material according to Eq. (3) (Table 2). This affords a convenient fixed point from which to derive the vapour pressure at other temperatures according to relationship:

$$
p(T)=p\left(T_{\mathrm{m}}\right) \exp \left\{\frac{-\Delta H}{R}\left(\frac{1}{T}-\frac{1}{T_{\mathrm{m}}}\right)\right\},
$$

where $p\left(T_{\mathrm{m}}\right)$ is the vapour pressure at the melting temperature and $\Delta H$ is the enthalpy of sublimation (if $T<T_{\mathrm{m}}$ ) or vaporisation (if $T>T_{\mathrm{m}}$ ). The vapour pressure of each material is given for $T=25^{\circ} \mathrm{C}$ for illustration. It is also possible to estimate the boiling temperature $\left(T_{\mathrm{b}}\right)$ at normal atmospheric pressure of these materials by extrapolating the vapour pressure vs. temperature curve until the pressure is $101325 \mathrm{~Pa}$ although the thermal stability of these compounds at such temperatures is questionable.

With such data, it is now possible to rank the series of UV absorbers according to their vapour pressure at any temperature. Inspection of Table 2 also shows the

\begin{tabular}{|c|c|c|c|c|}
\hline Substance & $M_{\mathrm{w}}(\mathrm{g} / \mathrm{mol})$ & $-\Delta H_{\text {fus }}(\mathrm{kJ} / \mathrm{mol})^{\mathrm{a}}$ & $-\Delta H_{\text {sub }}(\mathrm{kJ} / \mathrm{mol})^{\mathrm{b}}$ & $-\Delta H_{\mathrm{vap}}(\mathrm{kJ} / \mathrm{mol})^{\mathrm{c}}$ \\
\hline 2,4,4'-Trihydroxybenzophenone & 230.22 & 31.3 & 139.0 & 107.6 \\
\hline 2,4-Dihydroxy-4'-methoxybenzophenone & 244.25 & 35.6 & 138.3 & 102.7 \\
\hline 2,2'-Dihydroxy-4-methoxybenzophenone & 244.25 & 22.0 & 103.8 & 81.8 \\
\hline $2,2^{\prime}, 4,4^{\prime}$-Tetrahydroxybenzophenone & 246.22 & 28.0 & 178.5 & 150.5 \\
\hline 2-Hydroxy-4,4'-dimethoxybenzophenone & 258.27 & 37.6 & 121.1 & 83.5 \\
\hline $2,2^{\prime}$-Dihydroxy-4,4'-dimethoxybenzophenone & 274.27 & 33.2 & 130.2 & 96.9 \\
\hline 2-Hydroxy-4,4'-diethoxybenzophenone & 286.33 & 34.7 & 134.9 & 100.2 \\
\hline 2-Hydroxy-4-butoxy-4'-methoxybenzophenone & 300.68 & 33.7 & 126.3 & 92.6 \\
\hline 2-Hydroxy-4,4'-dibutoxybenzophenone & 342.43 & 54.0 & 148.0 & 94.0 \\
\hline
\end{tabular}

Table 1

Molecular weight, $\Delta H_{\text {fus }}, \Delta H_{\text {sub }}$ and $\Delta H_{\text {vap }}$ of UV absorbers

${ }^{\mathrm{a}}$ Measured by DSC, average deviation (five measurements) $<1 \mathrm{~kJ} / \mathrm{mol}$.

${ }^{\mathrm{b}}$ Calculated from Eq. (4) except for 2,4,4'-trihydroxybenzophenone which was measured directly.

${ }^{\mathrm{c}}$ Measured by TG, standard error of regression $<0.2 \mathrm{~kJ} / \mathrm{mol}$. 
Table 2

Melting point, vapour pressure and normal boiling temperature of UV stabilisers

\begin{tabular}{lcccc}
\hline Compound & $T_{\mathrm{m}}\left({ }^{\circ} \mathrm{C}\right)$ & $p\left(T_{\mathrm{m}}\right)(\mathrm{Pa})$ & $p\left(25^{\circ} \mathrm{C}\right)(\mathrm{nPa})$ & $T_{\mathrm{b}}(101325 \mathrm{~Pa})\left({ }^{\circ} \mathrm{C}\right)$ \\
\hline 2,4,4'-Trihydroxybenzophenone & 209.4 & 34.8 & 0.0173 & 413.5 \\
2,4-Dihydroxy-4'-methoxybenzophenone & 163.6 & 8.04 & 0.165 & 382.3 \\
2,2'-Dihydroxy-4-methoxybenzophenone & 69.8 & 0.226 & 950 & 354.3 \\
2,2',4,4'-Tetrahydroxybenzophenone & 198.8 & 24.5 & 0.0000745 & 329.7 \\
2-Hydroxy-4,4'-dimethoxybenzophenone & 117.2 & 2.67 & 26.0 & 388.2 \\
2,2'-Dihydroxy-4,4'-dimethoxybenzophenone & 139.1 & 3.72 & 1.82 & 372.0 \\
2-Hydroxy-4,4'-diethoxybenzophenone & 100.4 & 0.161 & 2.75 & 364.1 \\
2-Hydroxy-4-butoxy-4'-methoxybenzophenone & 72.4 & 0.0184 & 17.0 & 393.0 \\
2-Hydroxy-4,4'-dibutoxybenzophenone & 98.9 & 0.0739 & 0.524 & 421.9 \\
\hline
\end{tabular}

effect of hydrogen bonding and molecular weight on the volatility of the series of compounds. For example, the derivatives of 2,4,4'-trihydroxybenzophenone shows that methylation of the $4^{\prime}$ - and then 4-hydroxy group raises the vapour pressure but changing the substituents to ethyl and then butyl groups lowers the volatility of the 2-hydroxy-4,4'-alkoxybezophenones. By using the full vapour pressure vs. temperature relationships obtained from this work, it is possible to model evaporative loss during processing and subsequent use.

\section{Conclusions}

Thermogravimetry is a quick and convenient means of determining the vapour pressures of materials. The data may be used to rank materials according to their volatility and investigate the dependence of vapour pressure on structure. Such data is also useful in processing simulations and performance evaluation.

\section{References}

[1] E. von Hippel, The Sources of Innovation, Oxford University Press, Oxford, 1988.

[2] J. Durmis, M. Karvaš, P. Caucik, J. Holcik, Eur. Polym. J. 11 (1975) 219.

[3] E. Surova, Chem. zvesti 38(1) (1984) 93.

[4] B.F. Rordorf, A. Geoffroy, M. Szelagiewicz, E. Marti, in: H.G. Wiedemann (Ed.), Thermal Analysis, Proceedings of Sixth International Conference on Thermal Analysis, vol. 1, Bayreuth, FRG, Birkhäuser, Verlag, Basel, 1980, 313.
[5] C.G. de Kruif, T. Kuipers, J.C. van Miltenburg, R.C.F. Schaake, G. Stevens, J. Chem. Thermodyn. 13 (1981) 1081.

[6] V.V. Karpov, I.V. Krutovskaya, G.N. Rodionova, Russ. J. Appl. Chem. 57(6) (1984) 1252.

[7] W. McDowell, J. Soc. Dyers Colourists 89(5) (1973) 177.

[8] J. Pfefferkorn, H.G. Wiedemann, Prog. Vac. Microbal. Tech. 2 (1973) 221.

[9] M.A.V. Riberio da Silva, M.J.S. Monte, Thermochim. Acta 171 (1990) 169.

[10] K. Nishida, E. Ishihara, T. Osaka, M. Koukitu, J. Soc. Dyers Colourists 93 (1977) 52.

[11] T. Simizu, S. Ohkubo, M. Kimura, I. Tabata, T. Hori, J. Soc. Dyers Colourists 103 (1987) 132.

[12] M. Casserino, D.R. Belvins, R.N. Sanders, Thermochim. Acta 284 (1996) 145.

[13] J.W. Goodrum, E.M. Siesel, J. Thermal Anal. 44 (1996) 1251.

[14] W. Gückel, G. Synnatschke, R. Rittig, Pestic. Sci. 4 (1973) 137.

[15] W. Gückel, F.R. Rittig, G. Synnatschke, Pestic. Sci. 5 (1974) 393.

[16] W. Gückel, R. Kästel, J. Lewerenz, G. Synnatschke, Pestic. Sci. 13 (1982) 161.

[17] W. Gückel, R. Kästel, T. Kröhl, A. Parg, Pestic. Sci. 45 (1995) 27.

[18] J.P. Elder, J. Thermal Anal. 49 (1997) 897.

[19] P. Aggarwal, D. Dollimore, K. Alexander, J. Thermal Anal. 49 (1997) 595.

[20] P. Phang, D. Dollimore, Proceedings of 26th NATAS Conference, Cleveland, Ohio, USA, 1998, p. 508.

[21] S. Lerdkanaporn, D. Dollimore, J. Thermal Anal. 49 (1997) 879.

[22] P. Phang, D. Dollimore, Proceedings of 26th NATAS Conference, Cleveland, Ohio, USA, 1998, p. 495.

[23] D.M. Price, M. Hawkins, Thermochim. Acta 315 (1998) 19.

[24] I. Langmuir, Phys. Rev. 2 (1913) 329.

[25] L.N. Stewart, in: H.G. McAdie (Ed.), Proceedings of Third Toronto Symposium on Thermal Analysis, Chemical Institute of Canada, Toronto, 1969, p. 205.

[26] D.M. Hirst, Mathematics for Chemists, Macmillan, London, 1976. 